Lap splice over a grouted joint in a lattice girder system

K. Lundgren

Published in Magazine of Concrete Research, see journal homepage http://www.icevirtuallibrary.com/content/journals

"Permission is granted by ICE Publishing to print one copy for personal use. Any other use of these PDF files is subject to reprint fees." 


\title{
Lap splice over a grouted joint in a lattice girder system
}

\author{
K. Lundgren \\ Chalmers University of Technology
}

\begin{abstract}
Load-carrying in two directions in lattice girder slab systems by complementing with lapped reinforcement across the joints at the construction site was studied. A detailing of load-carrying joints without any reinforcement across the cast joint was considered. The behaviour of the cast joint between the precast concrete and the in situ cast concrete is very important. Two different surface treatments were tested in two types of detail tests of the cast joint: one type in which the cast joint was loaded in shear, and one in tension. Furthermore, the detailing of the joint between two precast concrete panels was tested in bending in full-scale tests. The detail tests were used to calibrate a friction model of the cast joint, which was then used in finite-element analyses (FEAs) of the full-scale tests. In the full-scale tests, the joints were strong enough to carry the applied load; thus, the failure mode was rupture of the reinforcement in all full-scale tests, and only one crack occurred-in the in situ cast concrete above the joint between the precast elements. However, the FEAs of the full-scale tests revealed that the detailing was sensitive to secondary cracking.
\end{abstract}

\section{Introduction}

To enable load carrying in two directions in lattice girder systems, transverse reinforcement in the precast concrete panels needs to be complemented with lapped reinforcement across the joints at the construction site. To ease production, it would be beneficial not to have any reinforcement across the cast joint between the precast concrete and the in situ cast concrete, as shown in Fig. 1. However, this raises questions as to whether the cast joint can transfer the required forces. This was addressed in the present project. In the studied detailing of the joint, a reinforcement mesh was placed in the in situ concrete across the joint, directly on the surface of the precast elements.

In Lundgren, ${ }^{1}$ similar joints were studied using twodimensional non-linear finite-element analyses (FEA). The behaviour of the cast joint was described using a friction model, calibrated from tests on grouted joints carried out by Nissen et $a l .^{2}$ It was concluded that the behaviour of the cast joint was very important for the

Department of Civil and Environmental Engineering, Division of Structural Engineering, Concrete Structures, Chalmers University of Technology, SE-412 96 Göteborg, Sweden

(MCR 600015) Paper received 2 November 2006; last revised 17 April 2007; accepted 4 June 2007 detailing. More experiments on grouted joints loaded in shear have been done by, for example, Gohnert. ${ }^{3}$ Gudmand-Høyer ${ }^{4,5}$ carried out tests on a detailing similar to the one studied here. It was a 'bubbledeck' intended to be used for load carrying in two directions, including shear stress transfer through a cast joint without crossing reinforcement. The tests resulted in brittle failures of the cast joints, which is naturally undesired behaviour. Therefore, further studies were needed to investigate whether it is possible to obtain safe solutions with such design of joints.

The behaviour of the joint was studied through a combination of experiments and non-linear FEAs. The main reason for this choice of method were to investigate the safety of the studied detail; it was judged that brittle failure by opening of the grouted joint must be avoided with a large safety margin. If this were to be investigated through experiments only, a large number of full-scale tests would be needed to ensure that the safety margin against premature brittle failure is large enough. Therefore, detail tests of the cast joint between the precast and the in situ concrete were carried out; by analysing these tests, a friction model of the cast joint could be calibrated. This model was then used in analyses of a lattice girder structure, which was also tested in full-scale experiments. Two types of surfaces of the precast elements were tested and analysed: a brushed surface and a surface with single grooves. Finally, the 


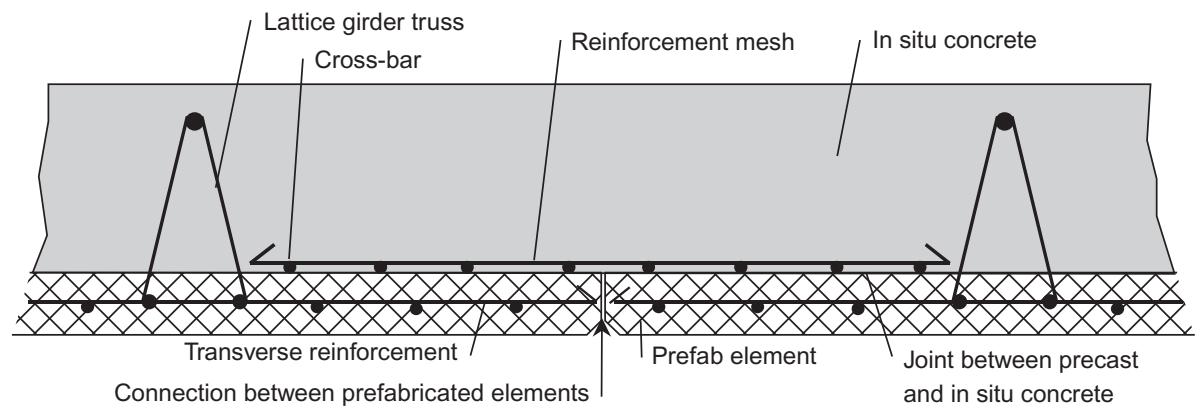

Fig. 1. Example of a splice in the joint between two lattice girder elements

safety of the detailing was examined by varying the properties of the grouted joint in analyses. In the following, the work is presented briefly; for a detailed analysis see Lundgren et al. $^{6}$

\section{Detail tests}

Two types of detail tests of the cast joint were carried out: one type in which the cast joint was loaded in shear and one in tension. Four tests of each type of surface and test were carried out; as two surfaces and two types of detail tests were used, this made 16 detail tests in total. The test specimens were composed of a prefabricated part and a part consisting of concrete cast in situ. The prefabricated parts were made in two different factories, where the two manufacturers used their ordinary surface treatment. Two manufacturers were chosen to obtain a good overall figure of the surface, among the lattice girders used in Sweden. One of the manufacturers made grooves with about $100 \mathrm{~mm}$ separation and a depth of about $10 \mathrm{~mm}$, while the other used a steel brush to make the surface rough. The depth of the roughness was approximately $7 \mathrm{~mm}$ over the whole surface. The prefabricated parts of all the test specimens (also for the full-scale tests) were cast at the same time. The in situ cast concrete for all specimens was cast on top of the prefabricated concrete when the prefabricated concrete had hardened for 14 days.

\section{Shear tests}

The shear test specimens were provided with stirrups to prevent the concrete from splitting at loading, see Fig. 2. Load was applied on the whole top surface and on the corresponding part of the bottom surface, see Fig. 2(d). Displacement transducers were used, measuring both the slip and the opening of the joint. The test specimens with surfaces having single grooves showed a large scatter; for the specimens with brushed surfaces, the scatter was relatively low. Moreover, the capacity of the cast joint was markedly higher for the brushed surface than for the surface with single grooves. The results of the shear tests are further discussed below in the section 'Results of analyses of shear tests'.

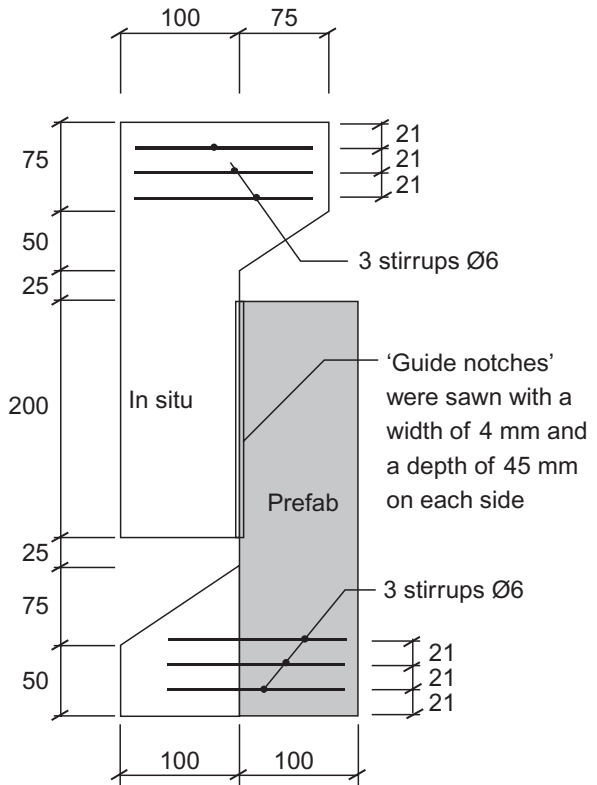

(a)

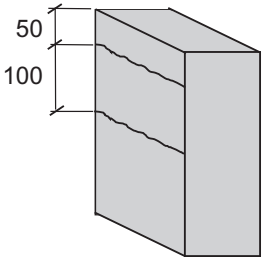

(b)

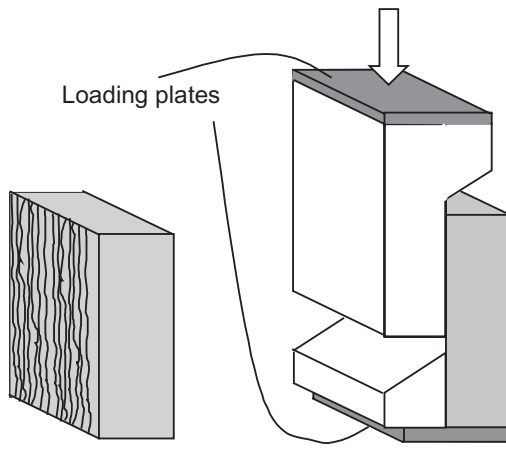

(c) (d)

Fig. 2. Geometry of shear test specimens: (a) whole specimens; (b) surface with grooves; (c) brushed surface. (d) loading (dimensions in $\mathrm{mm}$ ) 


\section{Wedge split tests}

The wedge split test (WST) was proposed by Linsbauer and $\mathrm{Tschegg}^{7}$ to measure the fracture energy $\left(G_{\mathrm{F}}\right)$ for homogeneous concrete, and has proved to be a reliable test method. In this project, the WST was used to increase knowledge of the joint behaviour for tensile loading; the adhesive strength and fracture energy of the joint could be evaluated. In total, eight WSTs were carried out. As with the shear test specimens, two different treatments of the prefabricated surfaces were used. The test specimens consisted principally of $200 \times 200 \times 150 \mathrm{~mm}^{3}$ cubes, where half of the specimens were of prefabricated and half in situ cast concrete; see Fig. 3, where a schematic procedure of the test set-up is shown.

Two steel plates with roller bearings were placed on top of the wedge test specimens. The splitting force was applied through a wedging device. Throughout the tests, the vertical load $F_{\mathrm{v}}$, the crack mouth opening displacement (CMOD) and the horizontal displacement were measured at the same level as the applied load. The applied horizontal splitting force $F_{\mathrm{sp}}$ was calculated from the measured vertical load, assuming the coefficient of friction for the roller bearing to be negligible; according to Karihaloo ${ }^{8}$ it normally varies between $0 \cdot 1 \%$ and $0 \cdot 5 \%$.

The behaviour of the WSTs was similar for both types of surface, with small scatter in the results. The difference was the maximum load, which was about twice as high for specimens with a brushed surface as for specimens with grooves. The results of the WSTs are further discussed in the section 'Results of analyses of wedge split tests'.

\section{Analyses to calibrate a model of the joint behaviour}

The detail tests were used to calibrate a friction model of the cast joint. Therefore, non-linear FEAs were used to model the detail tests. The program
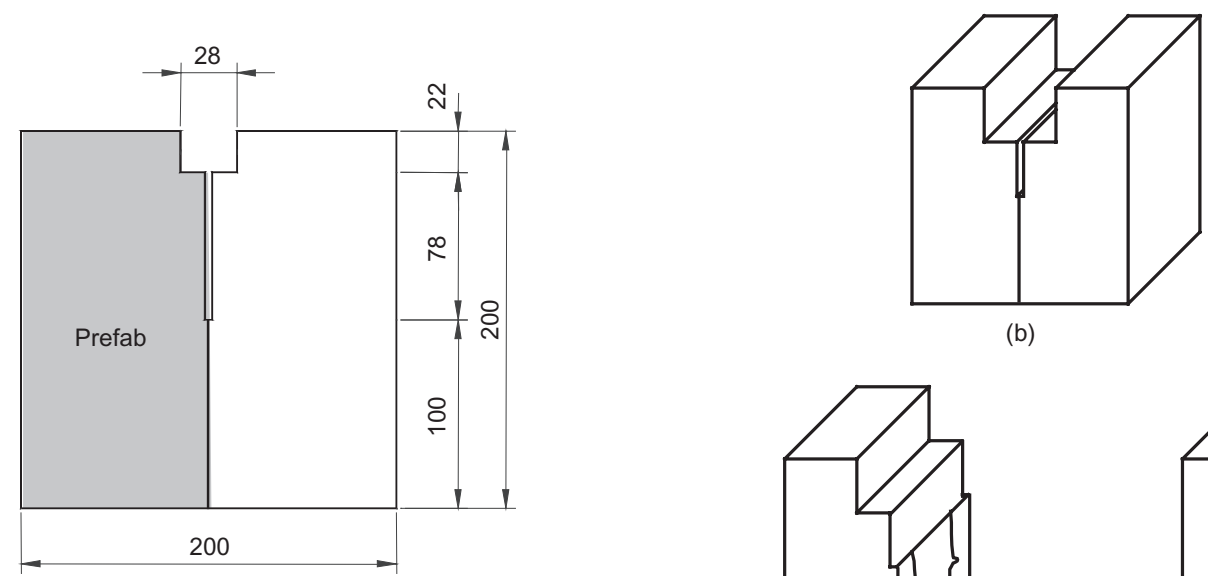

(b)

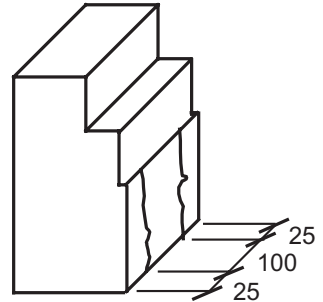

(c)

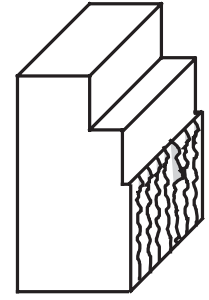

(d)

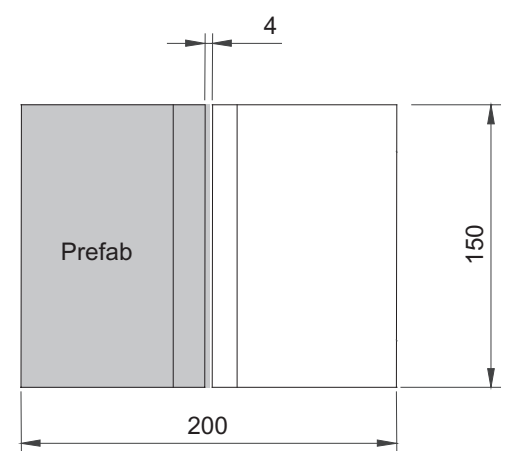

(a)

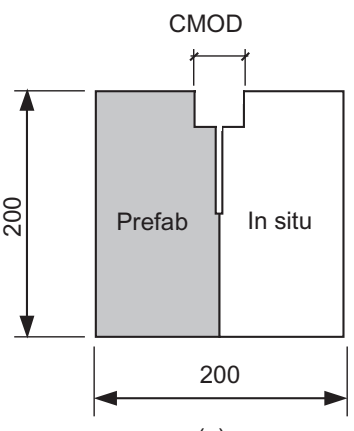

(e)

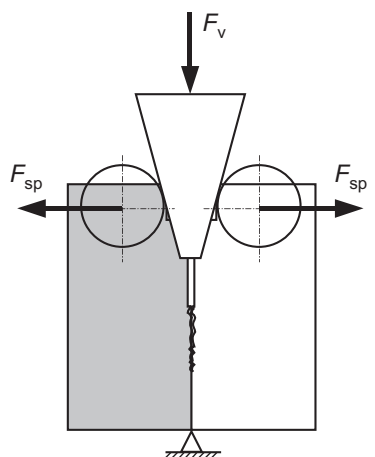

(f)

Fig. 3. WST specimens: (a) measurements; (b) three-dimensional sketch; (c) surface with grooves; (d) brushed surface; (e) measurement of CMOD; ( $f$ ) loading (dimensions in $\mathrm{mm}$ ) 
DIANA 8.1.2 was used in all analyses. All modelling was made in two dimensions, assuming plane stress. The concrete was modelled with four-node quadrilateral isoparametric plane stress elements. The cast joint was modelled with interface elements, with separate nodes for the precast and the in situ cast concrete, see Fig. 4. The concrete was modelled with a constitutive model based on non-linear fracture mechanics. The smeared crack concept was used, together with a rotating crack model based on total strain, see TNO. ${ }^{9}$ The deformation of one crack was smeared out over one element. The compressive strength measured in cylinder tests was used as input data in the analyses, ranging from $40 \cdot 8$ to $56.7 \mathrm{MPa}$. From the measured compressive strengths, the Young's modulus, tensile strength and fracture energy were calculated according to Comité Européen du Béton (CEB). ${ }^{10}$ Long-term effects such as creep and shrinkage were not included. Since these would have an influence when the joint is subjected to sustained tensile loading, these simplifications need further studies.

\section{Model of the joint behaviour}

The modelling of the joint interaction between the precast and the in situ cast concrete was of great importance for the results of the analyses. A friction model including adhesion was used, where the shear stresses, $\tau$, are limited in relation to the normal stresses, $\sigma_{\mathrm{n}}$, as

$$
|\tau|+\mu\left(\sigma_{\mathrm{n}}-f_{\mathrm{a}}\right)=0
$$

where

$\tau$ is the shear stress

$\mu$ is the coefficient of friction

$\sigma_{\mathrm{n}}$ is the normal stress acting on the interface, here defined as negative when in compression

$f_{\mathrm{a}}$ is the adhesive strength.

The friction model is shown in Fig. 5. The coefficient of friction, $\mu$, was assumed to be constant, while the adhesive strength, $f_{\mathrm{a}}$, was assumed to decrease at hardening. The hardening parameter $\kappa$ was defined from the resulting plastic deformations by

$$
\dot{\kappa}=\sqrt{\dot{u}_{\mathrm{n}}^{p^{2}}+\dot{u}_{\mathrm{t}}^{p^{2}}}
$$

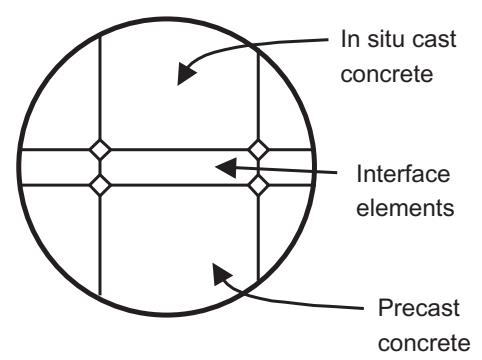

Fig. 4. Modelling with two-dimensional solid elements describing the concrete and interface elements describing the cast joint

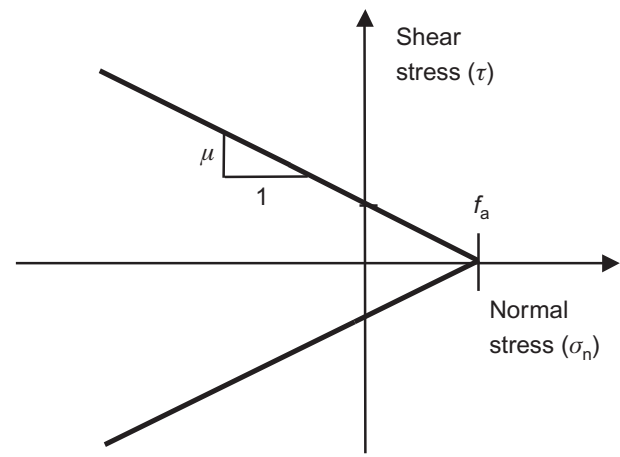

Fig. 5. Friction model used for the interface between the precast and the in situ cast concrete

where $\dot{u}_{\mathrm{n}}^{p}$ is the plastic part of the normal deformation over the joint and $\dot{u}_{\mathrm{t}}^{p}$ is the plastic part of the slip over the joint.

Important parameters in this model are the adhesive strength, $f_{\mathrm{a}}$, and coefficient of friction, $\mu$. Other parameters needed were the dilation parameter $\eta$ and elastic stiffnesses $D_{11}$ and $D_{22}$. The dilation parameter $\eta$ describes the magnitude of normal stresses that are created during slip if normal deformation is prevented, or the magnitude of normal deformations that will take place during slip if no normal stress is present. The stiffnesses $D_{11}$ and $D_{22}$ describe the relation between the stresses and the deformations in the elastic range: $D_{11}$ for the stress and the deformation in the normal direction, and $D_{22}$ for the shear stress and slip.

\section{Calibration procedure}

The adhesive strength $f_{\mathrm{a}}$ was evaluated and calibrated with the results from the WSTs. Thereafter, the coefficient of friction was evaluated and calibrated with the shear test results. Initially, all calibrations were made on average values of the experimental results. However, the test specimens with grooves in the prefabricated surface showed a large scatter in the shear test results; therefore two differently calibrated models were used for those. They used average and maximum values of the strength, respectively.

The results from the WSTs were organised and studied with inverse analysis, see Østergaard. ${ }^{11}$ The inverse analysis resulted in a bilinear relationship between the opening of the joint and the adhesive strength. As the shear stresses and deformations could be assumed to be negligible in the WSTs, only normal stresses and deformations took place. Therefore, the opening is approximately equal to the hardening parameter $\kappa$; thus, the hardening function for the adhesive strength, $f_{\mathrm{a}}(\kappa)$, could be evaluated. This provided starting values for the input for the FEA, and was later calibrated to more exact values. The fracture energy of the joint, $G_{\mathrm{F}}$, was determined as the area under the bilinear plot, see Fig. 6.

The elastic stiffness $D_{11}$ must be chosen so large that the elastic normal deformations in the WSTs are very

Magazine of Concrete Research, 2007, 59, No. 10 


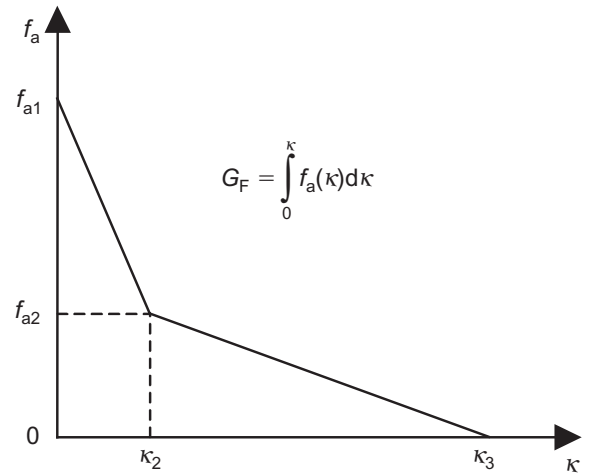

(a)

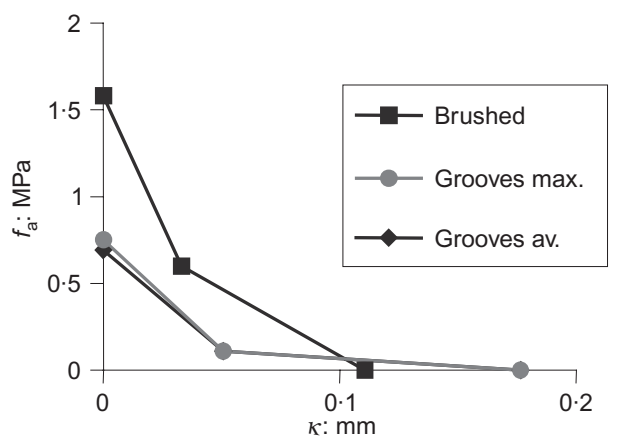

(b)

Fig. 6. (a) Bilinear relationship between the adhesive strength and the hardening parameter and (b) calibrated values of adhesive strength plotted against hardening parameter

small. It was chosen to be $3 \times 10^{11} \mathrm{~N} / \mathrm{m}^{3}$ for both types of surface.

Next, the shear test results were carefully examined. An approximate maximum shear stress was determined through the value of the peak load divided by the shear area. From the WST calibration, a value of $f_{\mathrm{a}}$ at maximum was achieved. As no outer normal stress was applied in the shear tests, it was assumed that the normal stress, $\sigma_{\mathrm{n}}$, was zero; this is an approximation as there can be normal stress locally in the joint, while the overall equilibrium demands that the average normal stress is zero. By inserting these approximations in equation (1), an approximate value of the coefficient of friction, $\mu$, was obtained. After that, $\mu$ was adjusted to get the FEA to correspond to the experiments. The calibrated value of $\mu$ was 3.7 for the brushed surface and 1.3 and 2.1 for the surface with single grooves, average and maximum values respectively, see Fig. 7. In a first step, an approximate value of the elastic stiffness $D_{22}$ was determined by the elastic stiffness in the test results, from the shear stress divided by the shear deformation. The elastic stiffness $D_{22}$ was then adjusted until the stiffness of the elastic part corresponded between the FEA and the experiments. The calibrated values of $D_{22}$ were $4.0 \times 10^{10} \mathrm{~N} / \mathrm{m}^{3}$ for the brushed surface and $3.5 \times 10^{10} \mathrm{~N} / \mathrm{m}^{3}$ for the surface

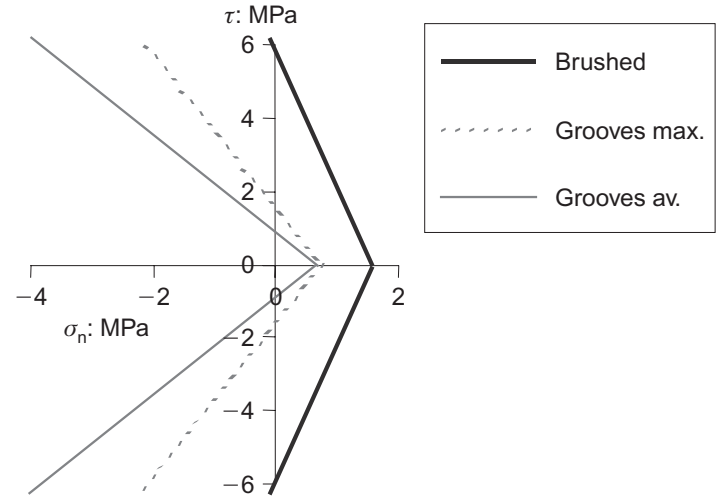

Fig. 7. Friction model for all three cases

with single grooves. Final calibrated parameters for all different cases are listed in Table 1.

\section{Model of shear tests}

The mesh and boundary conditions of the shear test model are shown in Fig. 8. The mesh size was $10 \mathrm{~mm}$; the thickness out of plane was $200 \mathrm{~mm}$ for the concrete elements and $110 \mathrm{~mm}$ for the cast joint layer. Friction layers were modelled at the support and loading plates. The nodes representing the loading plates were tied in all directions. Loading was controlled by applying a vertical displacement on the nodes at the top representing the loading plate. Chosen input data for the friction layers at the support and loading plates are shown in Table 2.

\section{Results of analyses of shear tests}

The load plotted against vertical joint slip from the FEA and the shear tests is presented in Fig. 9. The vertical joint slip in the analyses was evaluated similarly to how it was measured in the tests, to ease the comparison. It was calculated as the difference in displacements in nodes that were situated where the measuring devices were placed in the tests; see Fig. 9(d).

Table 1. Calibrated parameters of the joint model, input for FEA

\begin{tabular}{l|c|c|c}
\hline Parameter & $\begin{array}{c}\text { Brushed, } \\
\text { average }\end{array}$ & $\begin{array}{c}\text { Grooves, } \\
\text { average }\end{array}$ & Grooves, max. \\
\hline$\mu[-]$ & $3 \cdot 7$ & $1 \cdot 3$ & $2 \cdot 1$ \\
$\eta[-]$ & $0 \cdot 5$ & $0 \cdot 5$ & $0 \cdot 5$ \\
$D_{11}: \mathrm{N} / \mathrm{m}^{3}$ & $3 \times 10^{11}$ & $3 \times 10^{11}$ & $3 \times 10^{11}$ \\
$D_{22}: \mathrm{N} / \mathrm{m}^{3}$ & $4 \times 10^{10}$ & $3 \cdot 5 \times 10^{10}$ & $3 \cdot 5 \times 10^{10}$ \\
$f_{\mathrm{a} 1}: \mathrm{MPa}$ & $1 \cdot 58$ & $0 \cdot 69$ & $0 \cdot 75$ \\
$\kappa_{1}: \mathrm{mm}$ & 0 & 0 & 0 \\
$f_{\mathrm{a} 2}: \mathrm{MPa}$ & $0 \cdot 599$ & $0 \cdot 109$ & $0 \cdot 109$ \\
$\kappa_{2}: \mathrm{mm}$ & $0 \cdot 033$ & $0 \cdot 05$ & $0 \cdot 05$ \\
$f_{\mathrm{a} 3}: \mathrm{MPa}$ & 0 & 0 & 0 \\
$\kappa_{3}: \mathrm{mm}$ & $0 \cdot 11$ & $0 \cdot 17$ & $0 \cdot 17$ \\
$G_{\mathrm{F}}: \mathrm{N} / \mathrm{m}$ & 59 & 27 & 29 \\
\hline
\end{tabular}



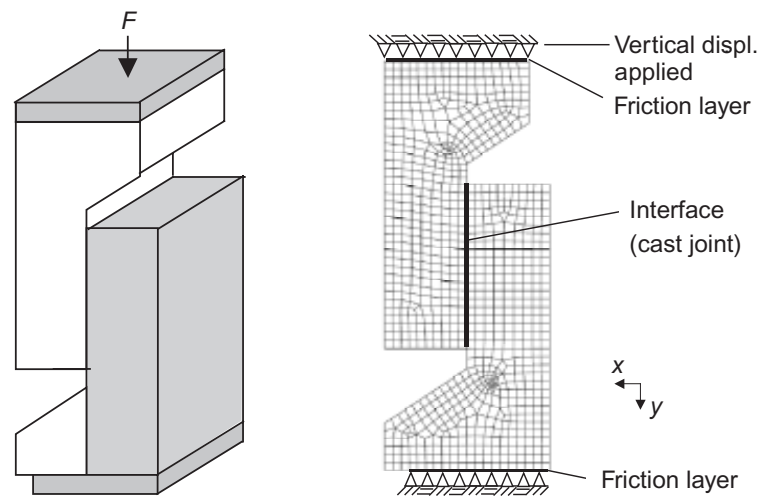

Fig. 8. (a) Principle sketch of shear test; (b) finite-element model

Fig. 9(a) shows the result for the specimens with a brushed surface. The FEA was without cracks, which led to a linear response until the peak load, while horizontal cracking occurred in the tests, as shown in
Table 2. Input data for the friction layers at the support and loading plates in the shear test model

\begin{tabular}{l|c|c|c|c}
\hline$\mu[-]$ & $\eta[-]$ & $D_{11}: \mathrm{N} / \mathrm{m}^{3}$ & $D_{22}: \mathrm{N} / \mathrm{m}^{3}$ & $f_{\mathrm{a}}: \mathrm{MPa}$ \\
\hline 0.4 & $0 \cdot 1$ & $1 \times 10^{11}$ & $1 \times 10^{11}$ & 0 \\
\hline
\end{tabular}

Fig. 9(b). This explains the difference in the total joint slip for higher loads. For lower loads, both the force and the slip agree well between the FEA and the tests; in the analyses the same stiffness is found until collapse of the joint. The results for the specimens with surfaces having single grooves are shown in Fig. 9(c), where the large scatter in the experimental results can be seen. The maximum load in the analyses corresponds well with the measured ones, as can be expected since input for the cast joint was calibrated until agreement was found. Furthermore, the behaviour after maximum load

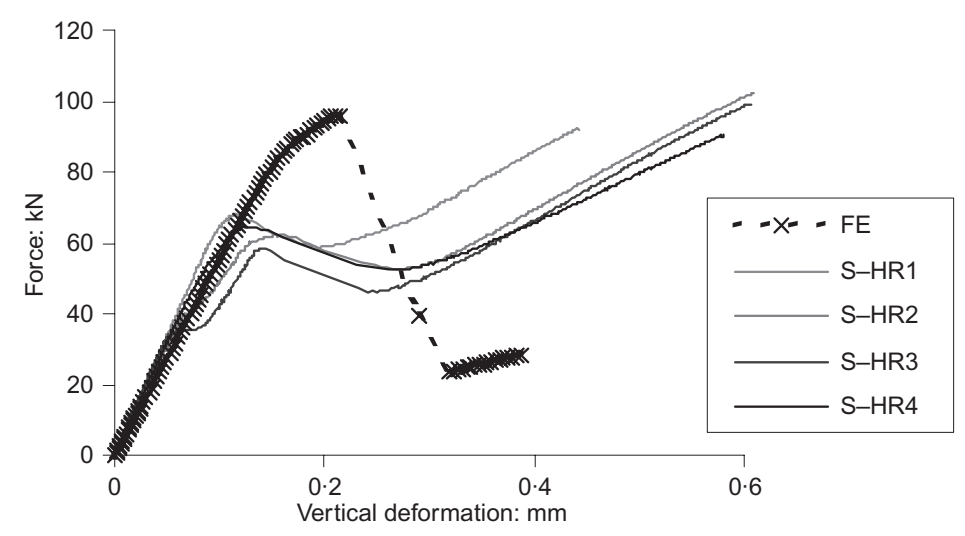

(a)

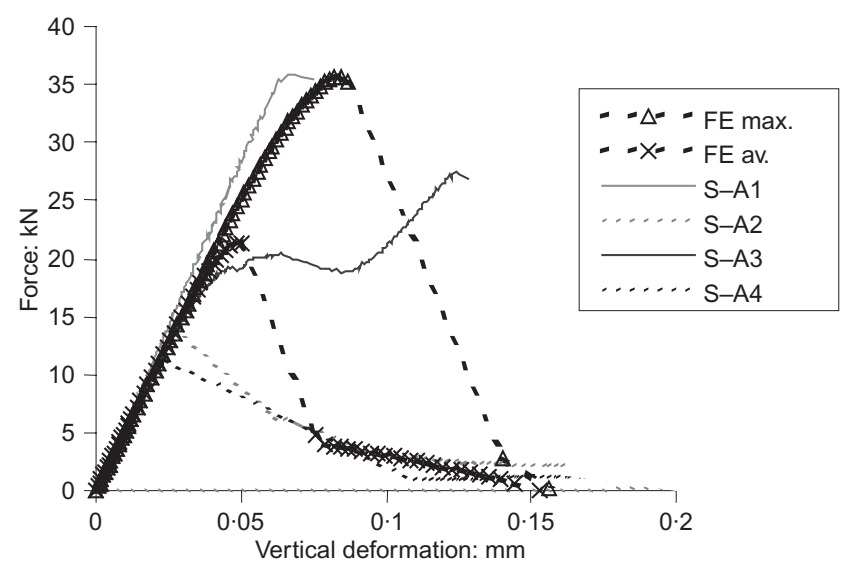

(c)

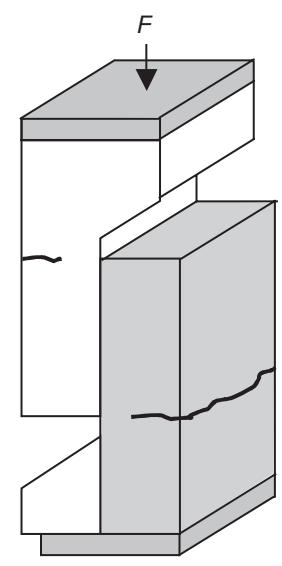

(b)

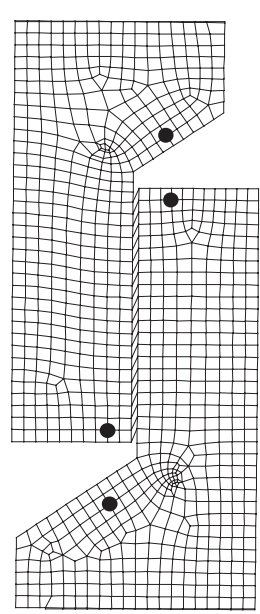

(d)

Fig. 9. Comparison of load plotted against vertical deformation over the cast joint in shear tests and analyses. (a) Specimens with brushed surface. (b) Horizontal cracking occurred in the tests of the specimens with brushed surface. (c) Specimens with surfaces having single grooves. (d) The vertical deformation over the joint was calculated as the average of the differences in vertical displacements in the marked nodes (deformed mesh shown) 
was very brittle in the analyses; in the tests it could seldom be followed, as it was too brittle.

The normal deformations over the cast joint obtained in the FEA and the experiments are compared in Fig. 10. Slightly larger horizontal deformations were measured in the tests than were obtained in the analyses. However, the trend with increasing horizontal deformation just before and especially at maximum load is similar.

\section{Model of wedge split tests}

The geometry of the WST was modelled as shown in Fig. 11, with mesh size of $8 \mathrm{~mm}$. The support in the bottom of the WST was modelled by locking respective nodes in the $y$-direction and the two nodes in the centre locked in the $x$-direction. Interface elements were used to model the cast joint between the precast and in situ cast concrete.

\section{Results of analyses of wedge split tests}

The load plotted against CMOD for the WSTs and their FEAs are compared in Fig. 12. As can be seen, the results correspond well, which indicates that the parameters of the joint are properly calibrated. The analyses converged until the CMOD was $0.2 \mathrm{~mm}$ for the brushed surface and $0 \cdot 15 \mathrm{~mm}$ for the surface with grooves; as can be seen in Fig. 12, the solutions thereafter were unstable.

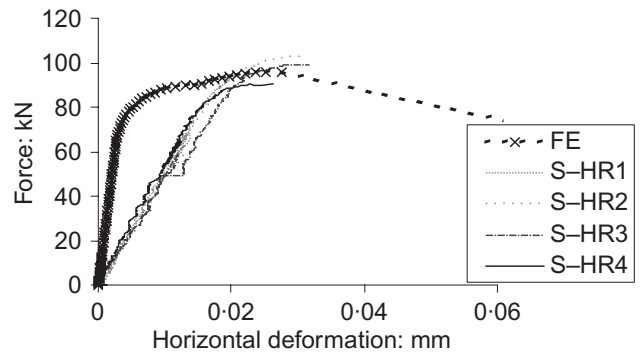

(a)

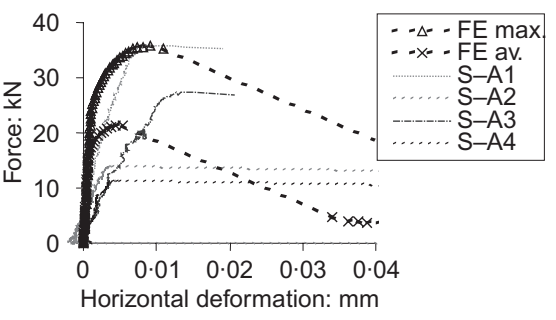

(b)

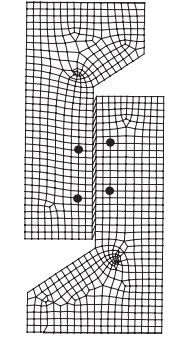

(c)
Fig. 10. Comparison of load plotted against horizontal deformation over the cast joint in shear tests and analyses: (a) specimens with brushed surface; (b) specimens with surfaces having single grooves; (c) the horizontal deformation over the joint was calculated as the average of the differences in horizontal displacements in the marked nodes (deformed mesh shown)

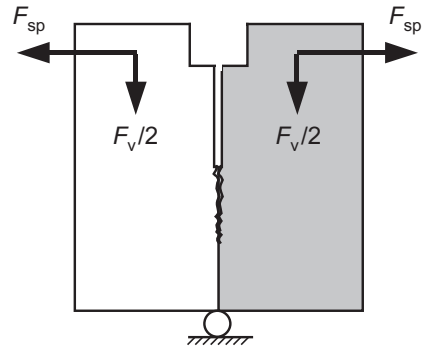

(a)

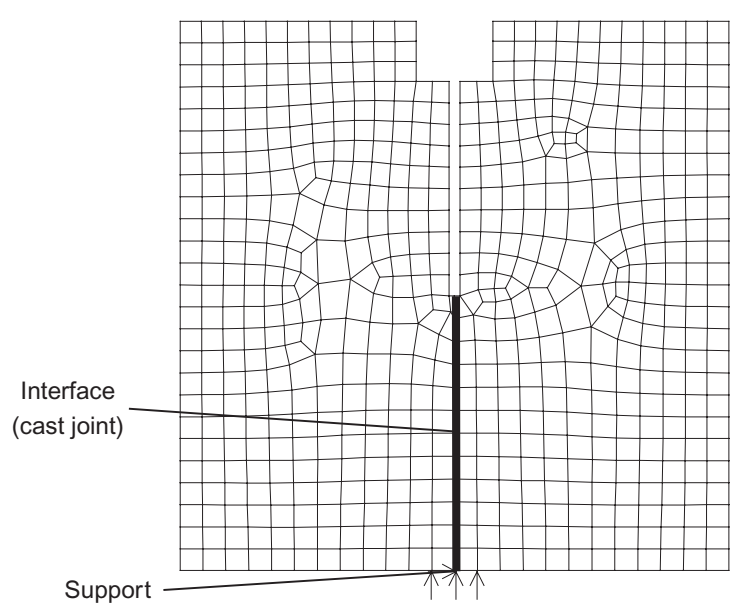

(b)

Fig. 11. (a) Principle sketch of WST; (b) finite-element model

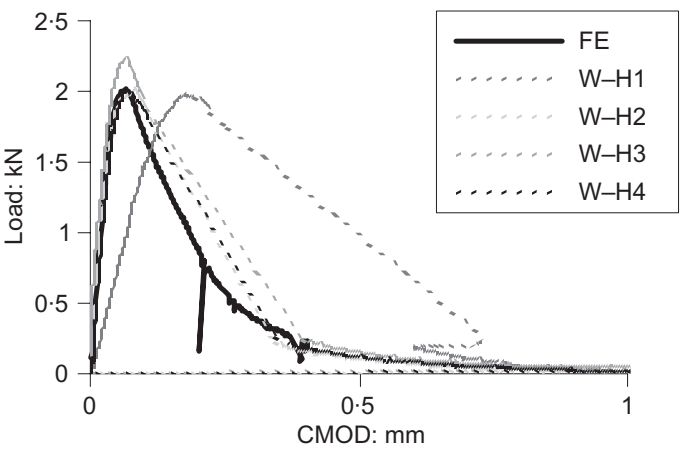

(a)

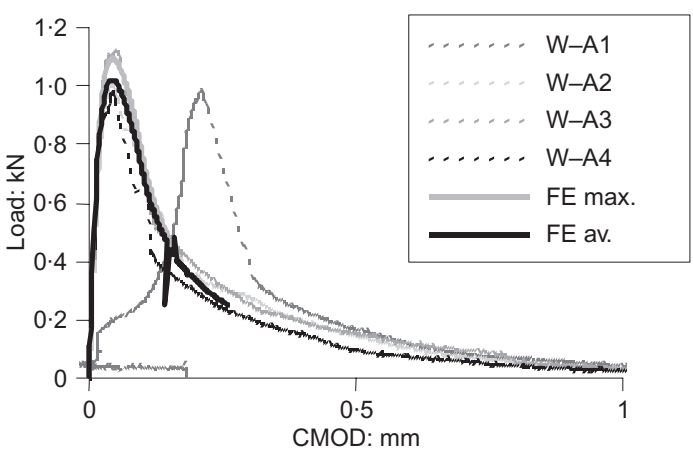

(b)

Fig. 12. Load plotted against CMOD for WSTs and FEAs of them: (a) specimens with brushed surface; (b) specimens with surfaces having single grooves 


\section{Full-scale tests and analyses}

The detailing of the joint between two precast concrete panels was tested in bending in full-scale tests. Three tests of each surface were carried out; as two surfaces were investigated, this required a total of six full-scale tests.

\section{Test specimens}

The geometry of the full-scale tests was lattice girders composed of two precast elements next to each other, with a reinforcement mesh placed directly on the surface over the joint. Concrete was cast in situ on top, see Fig. 13. The test specimens had a total width of $500 \mathrm{~mm}$ in the plane. The compressive strength of the concrete was tested on wet stored cylinders, $150 \times 300 \mathrm{~mm}^{2}$. The properties of the reinforcement mesh were tested in tensile tests.

\section{Test set-up and results}

The full-scale tests were performed to study the structural behaviour of the joint in the lattice girder structure. The test specimens were loaded by two point loads in four-point bending, see Fig. 14. Strain gauges were placed on the centre bars of the reinforcement meshes.

The structural behaviour was similar for all six fullscale tests, with only one crack in all tests, at mid-span in the in situ cast concrete over the joint. The failure mode was rupture of the reinforcement bars in all tests. A typical load plotted against deformation plot is shown in Fig. 15. The structural behaviour corresponded to linear elastic response until a load of about $11 \mathrm{kN}$. Instantly, the first crack appeared and the load made a small dip. Thereafter, load and deflection increased to the values of approximately $18-20 \mathrm{kN}$ and $1.6-1.9 \mathrm{~mm}$ respectively. At this load, yielding of the reinforcement occurred and the initiated crack propagated. At the yielding stage, the load remained almost constant, besides a very small increase of load owing to hardening of the steel. Semi-collapse occurred when one of the longitudinal bars ruptured at the load, approximately at $20 \mathrm{kN}$ and deflection about $18-21 \mathrm{~mm}$. The remaining longitudinal bars provided further loadcarrying capacity under a decreasing load until they also ruptured. Total collapse of the structure occurred at a deflection of about $28-33 \mathrm{~mm}$. The results from the tests are further described in the section 'Results of analyses of full-scale tests'.

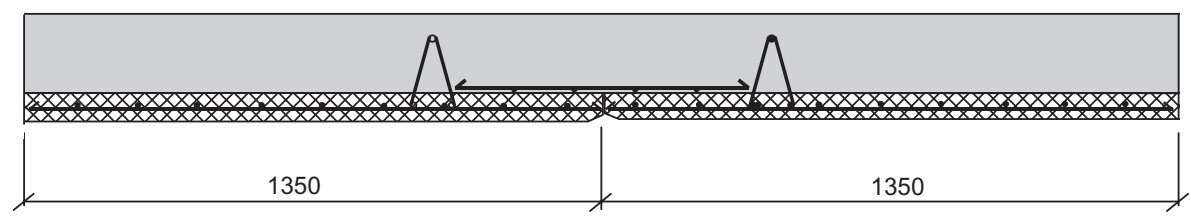

(a)

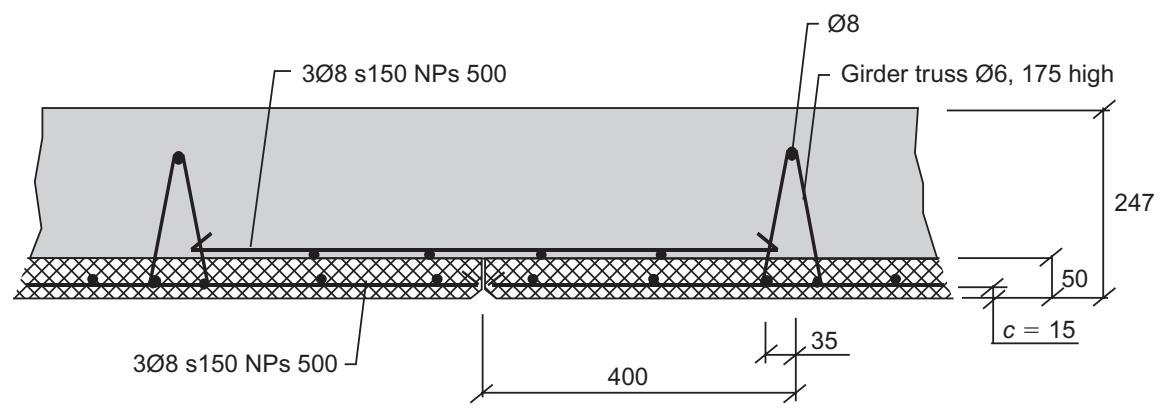

(b)

Fig. 13. Geometry of the tested lattice girder structure: (a) overview; (b) detail at the joint (dimensions in mm)

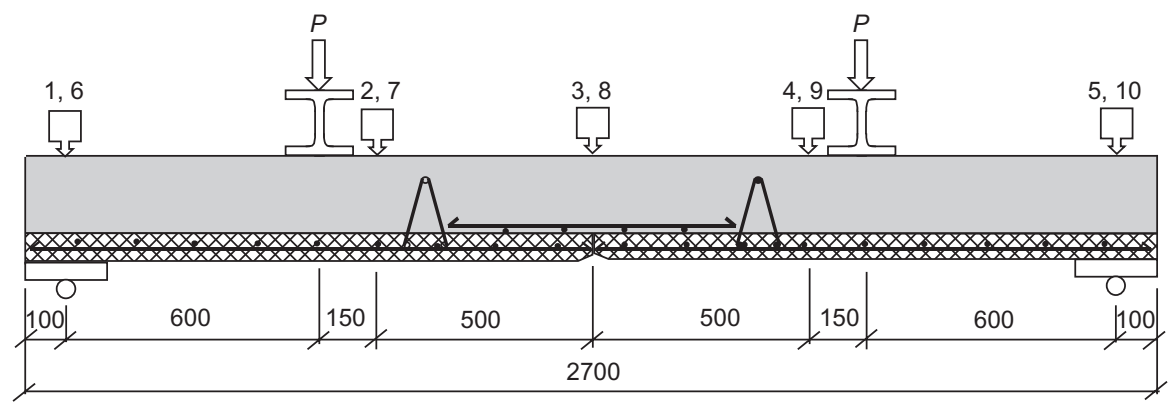

Fig. 14. Test set-up with displacement transducers and loads (dimensions in mm) 


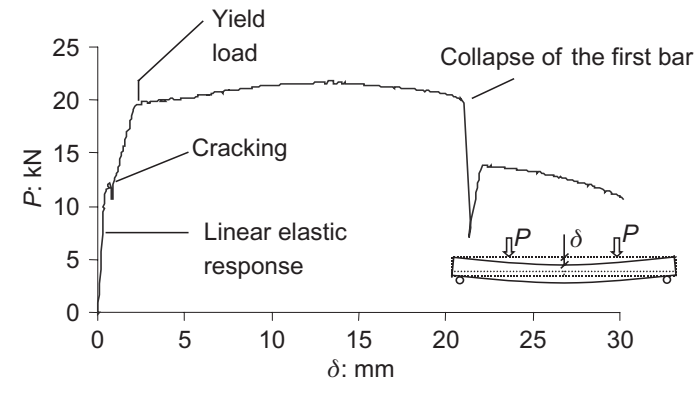

Fig. 15. General load plotted against deflection and behaviour of the full-scale tests

\section{Model of full-scale tests}

In the model of the full-scale tests, some simplifications were made to decrease the number of elements and thereby speed up the analyses. The simplification was to model the right part from the right lattice girder truss with only beam elements, see Fig. 16. The left part was modelled in detail, with the cast joint modelled with interface elements. The reason for this asymmetric choice was that, in an experiment, the structure would not be symmetric if failure were determined by opening of the cast joint.

The reinforcement in the left part was modelled with truss elements. Special interface elements were used between the reinforcement and the concrete, describing a bond-slip relation. The relation was chosen according to $\mathrm{CEB},{ }^{10}$ assuming unconfined concrete and other bond conditions. The welds in the reinforcement mesh were modelled with the reinforcement and the concrete nodes tied to each other at the points of the welds, see

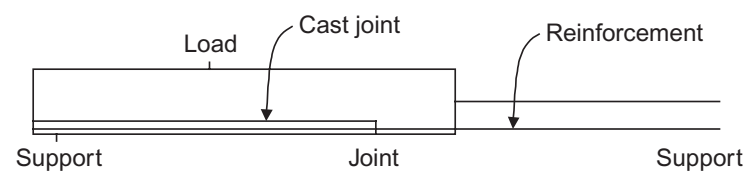

(a)

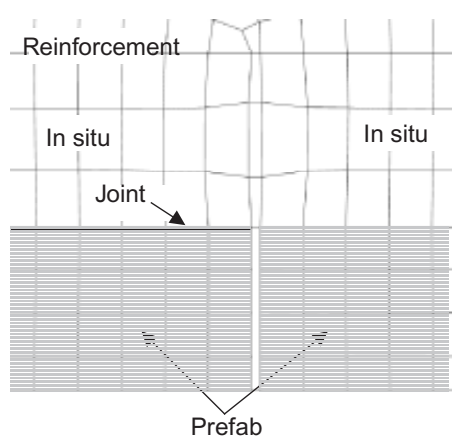

(b)

Fig. 16 (a) Model of full-scale tests with detailed modelling of the left part and the right part more simply modelled with beam elements; (b) detail of the modelling of the prefabricated and in situ cast concrete and the cast joint
Fig. 17. The lattice girder truss was modelled by tying the in situ and precast nodes to each other in the centre of the truss. This is a simplification, while the real behaviour is that the truss only limits the joint from opening at the points where the truss crosses the joint.

The reinforcement in the beam part was modelled as embedded reinforcement; full interaction was assumed and bond slip was not included. The constitutive behaviour of the reinforcement was modelled by the von Mises yield criterion with associated flow and isotropic hardening. The stress-strain relationship used corresponded to the measured force plotted against strain in the tensile tests of the reinforcement.

At the supports, steel plates and roller bearings were used in the tests. In the part modelled in detail, the steel plate was modelled so that the nodes representing the plate were tied to the centre node, thus forcing the nodes to remain in a straight line, but allowing for rotation. The centre node was supported for displacement in the $x$ - and $y$-directions. Also for modelling of the loading plates on the top of the beam, the nodes were tied to remain in a straight line. On the right part with beam elements, only one node in the centre of the plates was supported in the $y$-direction respectively loaded.

\section{Results of analyses of full-scale tests}

The FEAs of full-scale and test results were compared. In all analyses, as in the tests, a main crack appeared in the in situ cast concrete above the joint. In the analysis with brushed surface, failure was determined by rupture of the reinforcement, as in the tests. However, in the analysis with a surface having single grooves, the cast joint fractured, when using either the average or the maximum values from the calibration.

Results from tests and analyses with the brushed surface are shown in Fig. 18. As can be seen in Fig. 18(b), there is good agreement for the first part of the curves, with cracking at a load of about $11 \mathrm{kN}$ and yielding at a load of about $19 \mathrm{kN}$. Fig. 18(c) describes the crack pattern in the analysis just before collapse of the structure. One main crack, in the in situ cast concrete above

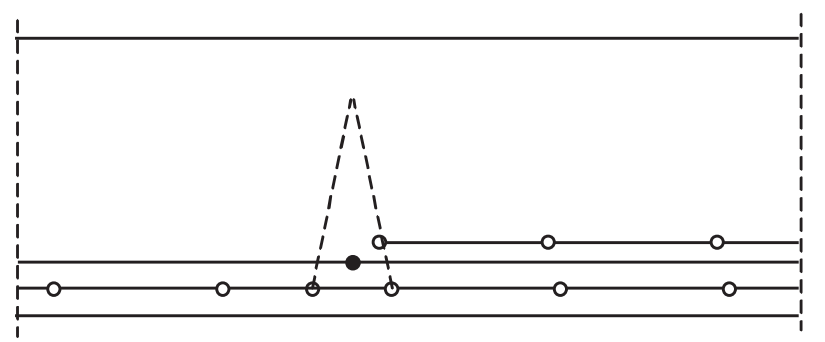

Fig. 17. Part of the model of the full-scale tests. Open circles mark where the concrete and reinforcement nodes were tied to each other. The solid circle marks where the nodes of the precast concrete and the in situ concrete were tied to each other 


\section{Lundgren}

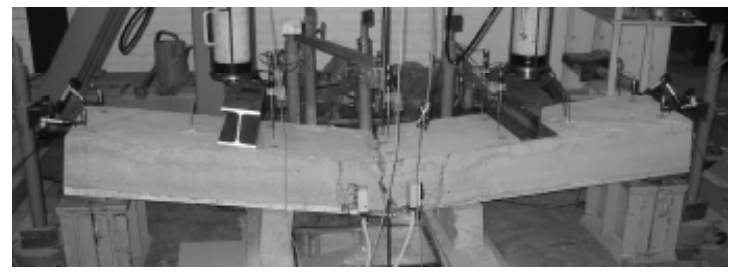

(a)

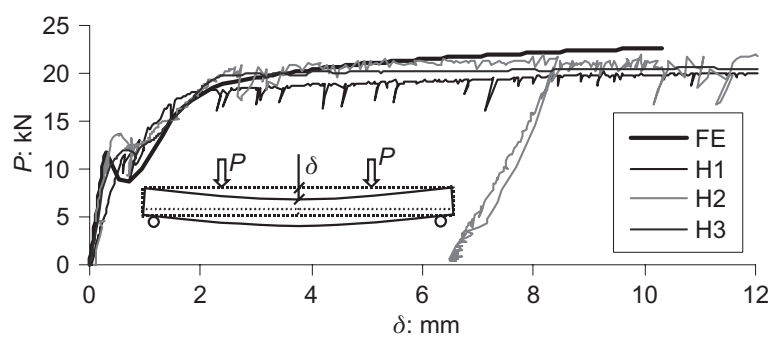

(b)

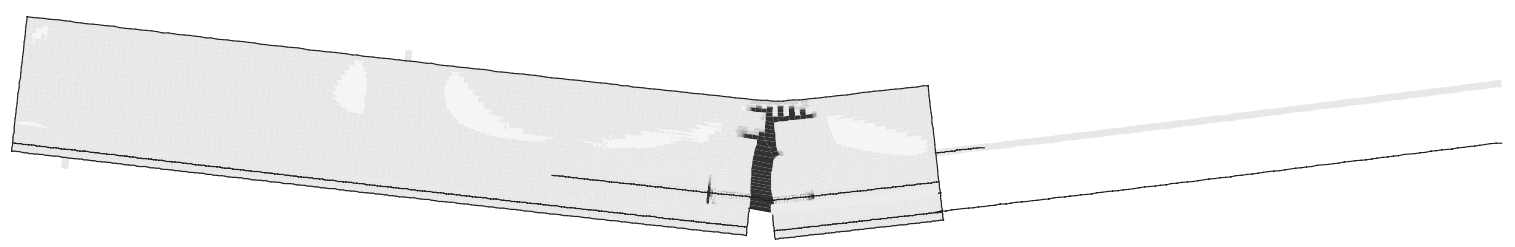

(c)

Fig. 18. Full-scale test and analysis with brushed surface: (a) experiment; (b) load plotted against mid-span deflection; (c) crack pattern (dark areas are cracked) in analysis

the joint in the mid-span, was formed. Smaller cracks were also formed at the first cross-bars in the reinforcement mesh over the joint; these, however, were very small. Failure in this analysis was determined by rupture of the reinforcement, at a mid-span deflection of about $10 \mathrm{~mm}$, compared with about $30 \mathrm{~mm}$ in the tests. The large difference in the mid-span deflection when rupture of the reinforcement bar occurred, between the tests and the analysis, is attributable to the assumed bond-slip relation. In reality, the bond stress will drop when the reinforcement starts yielding. This was not included in these analyses; therefore, they were not capable of predicting a correct mid-span deflection when rupture of the reinforcement occurred.

Load plotted against mid-span deflection from the tests and analyses of the specimens with surface having single grooves is shown in Fig. 19. Again, there is good agreement for the first part of the curves. However,

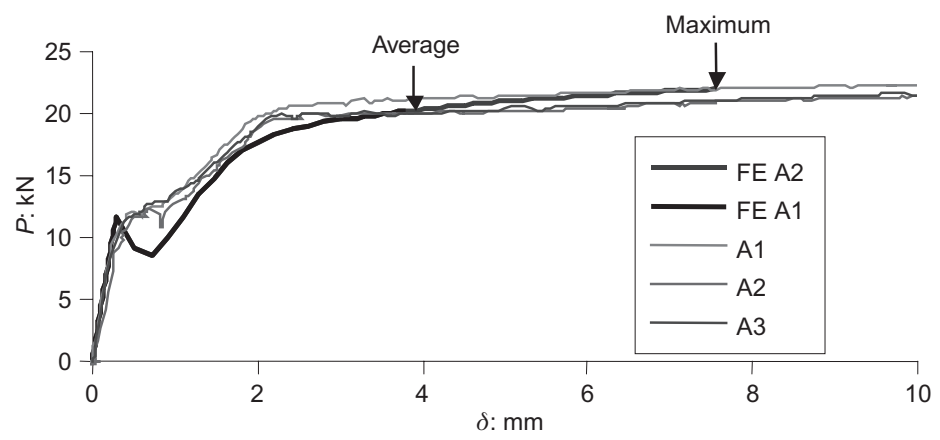

(a)

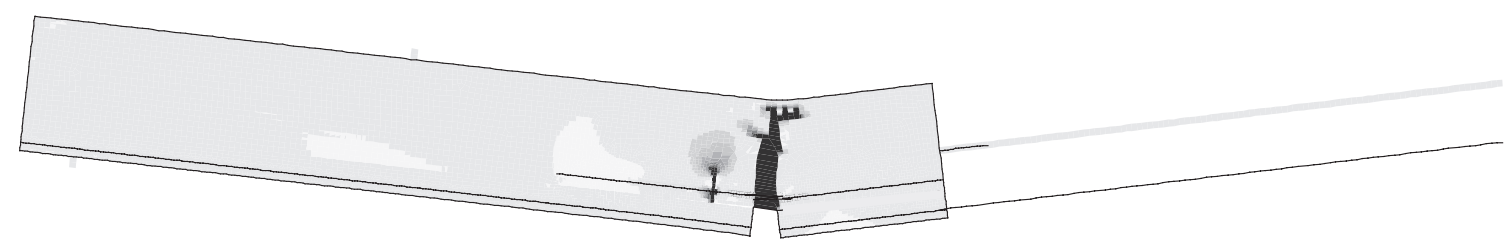

(b)

Fig. 19. (a) Load plotted against mid-span deflection, in FEA and tests of specimens with surfaces having single grooves. Especially marked are the points where the FEAs stopped. (b) Crack pattern and deformed mesh before collapse, from analysis with average values (results from analysis with maximum values are similar) 
both of the analyses stop at a mid-span deflection, which is a lot smaller than was obtained in the tests; analysis with average values stops at mid-span deflection $3.8 \mathrm{~mm}$, and analysis with maximum values at $7.9 \mathrm{~mm}$. In both analyses, the joint opening increased greatly in the final steps, and thus indicated that the failure mode in these analyses was opening of the joint.

Crack patterns in the analyses are shown in Fig. 19(b). As can be seen, there was one main crack in the in situ cast concrete above the joint in both of the analyses, as was the case with the tests. However, in both of the analyses there was also one crack that appeared at the location of the first cross-bar in the reinforcement mesh, which appeared just before maximum load. Most probably, the appearance of this crack initiated opening of the joint, which, as already mentioned, was the failure mode in both these analyses.

This contradicts what was found in the tests, where the final failure mode was rupture of the reinforcement. One reason for the difference might be the choice of tying the reinforcement to the concrete at the locations of the cross-bars of the reinforcement mesh. This might have caused too large a restraint in the analyses compared with the experiments, so that the second crack was initiated too easily in the analyses. This is confirmed when the strain in the reinforcement in the analyses is compared with what was measured in the tests, see Fig. 20. Only results from analysis with average values are shown, but the results were similar in the analysis with maximum values, and also in the analysis of the specimen with brushed surface.

When studying the measured strains along the reinforcement bar across the joint, it was clear that the cross-bars had provided very little restraint, as there was no distinct increase in strain at the location of the cross-bars. To better correspond to this situation, an analysis was performed without the ties between the reinforcement and the concrete at the locations of the cross-bars, using the average values of calibrated input for the surface with single grooves. Load plotted against mid-span deflection from this analysis is compared with test results in Fig. 21(a). As can be seen, the maximum obtained mid-span deflection was a lot larger

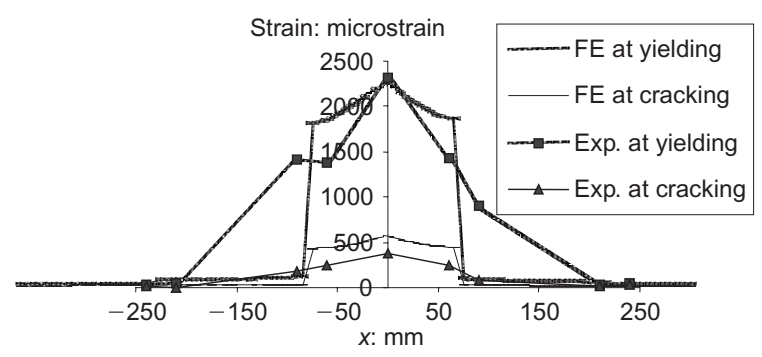

Fig. 20. Strain in the reinforcement at some load levels. From test specimens with single grooves and corresponding analysis with average values

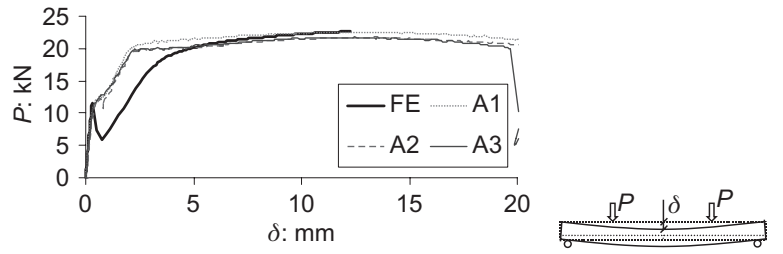

(a)

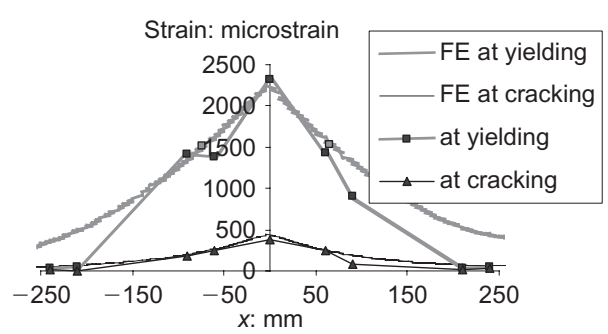

(b)

Fig. 21. Results from FEA with average values of surfaces having single grooves and without ties corresponding to the welds in the reinforcement. (a) Load plotted against mid-span deflection; (b) strain in the reinforcement at some load levels

in this analysis than when the ties were included: $12.2 \mathrm{~mm}$ compared with $3.8 \mathrm{~mm}$. The failure mode in this analysis was rupture of the reinforcement with only one crack in the in situ cast concrete above the joint, similar to the tests. In Fig. 21(b), the strain in the reinforcement in the analysis is compared with measured strain for two load levels. As can be seen, good agreement is found when no ties were assumed between the reinforcement and the concrete, much better than when the ties were present; compare Fig. 20.

Thus, it can be concluded that the analysis without ties better represents the tested specimen than the analysis with ties at the locations of the cross-bars in the reinforcement mesh. This conclusion is based on the fact that the failure mode in the analysis without ties corresponds to the one obtained in the test, and that the strain along the reinforcement bar better corresponds to measured values. Furthermore, it can be concluded that the restraint of the cross-bars has a negative influence on the behaviour. It is important to note that in the tested specimens, the reinforcement mesh was placed directly on the precast concrete, without any distances. It is therefore most likely that the cross-bars were not very well confined, and hence did not contribute any major restraint. If, however, the reinforcement mesh were turned upside down, with the reinforcement crossing the joint directly on the precast concrete, a situation with better confined cross-bars would be achieved. In view of the analysis results here, this would not be beneficial.

\section{Parameter study in analyses of full-scale tests}

It was clear that the grouted joint had sufficient capacity not to be limiting in the full-scale tests. This 
result could also be found in the analyses: for the specimens with surfaces having single grooves, the joint had sufficient capacity when no restraint from the crossbars in the reinforcement mesh was included, while for the specimens with brushed surface, the joint had sufficient capacity even when the restraint was included. One very important question is how much safety there is with the tested design of the joint. For the specimens with surfaces having single grooves, the analyses in the previous section already indicate this: if the cross-bars in the reinforcement mesh were more confined than in the present tests, the joint would most likely be limiting. Therefore, it cannot be recommended to use the studied detailing for load-carrying purposes with prefabricated elements having this type of surface.

The specimens with brushed surfaces, on the other hand, managed to reach rupture of the reinforcement in the analyses even when full restraint was assumed between the cross-bars and the concrete. The question is therefore how sensitive the detailing is. To investigate this, some variations were examined. The parameters describing the cast joint obviously have a very strong influence on the behaviour of the structure. These parameters will be influenced by the conditions when the cover concrete is cast in situ. The conditions at the construction site can be difficult to control: for example, how can it be ensured that there is no dust, snow or oil from formworks at the surface of the prefabricated concrete when the in situ concrete is cast? It was judged that this would mainly influence the adhesive strength.

Furthermore, it needs to be considered that the tests and FEAs carried out were in two dimensions, with load-carrying only in one direction. However, in real applications, the slab will be load-carrying in two directions. The load-carrying in the main direction will also create shear stresses in the cast joint, which will be added to those investigated in this work. In Lundgren et al. ${ }^{6}$ a simplified way to take this shear stress into account in the analyses is outlined, which in short means that the shear stresses acting in the other direction can be taken into account in a simplified way by decreasing the adhesive strength.

Owing to these two reasons just discussed, there was a need to check the extent to which varying values of the adhesive strength would affect the results. The coefficient of friction and also the other parameters of the joint are mainly dependent on the roughness of the surface. As this is created in the factory, it is easier to control. These parameters were therefore not varied.

Thus, two more analyses were carried out for the specimen with brushed surface

(a) with half the adhesive strength as found in the calibration of the grouted joint;

(b) with zero adhesion in the grouted joint.

Other values in these two analyses were chosen as in the original calibration of the brushed surface.

The results from analyses with half adhesive strength are shown in Fig. 22. The limiting failure mode was rupture of the reinforcement. Only one main crack appeared, even though smaller cracks were visible at the position of the cross-bars of the reinforcement mesh. However, opening of the joint was probably

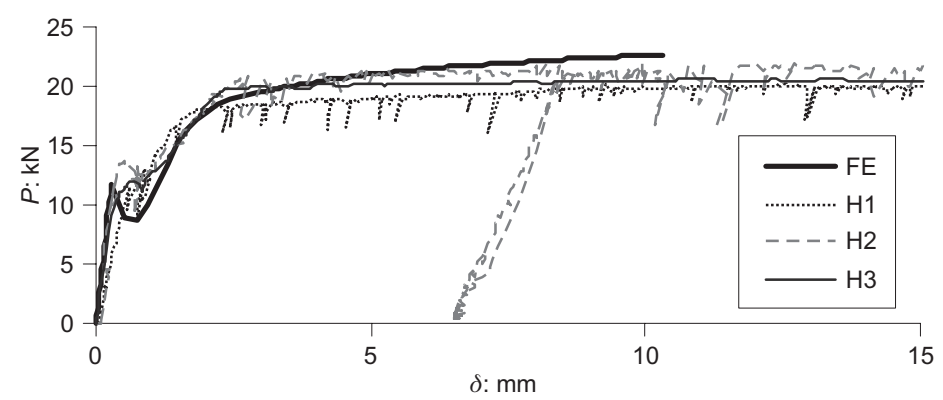

(a)
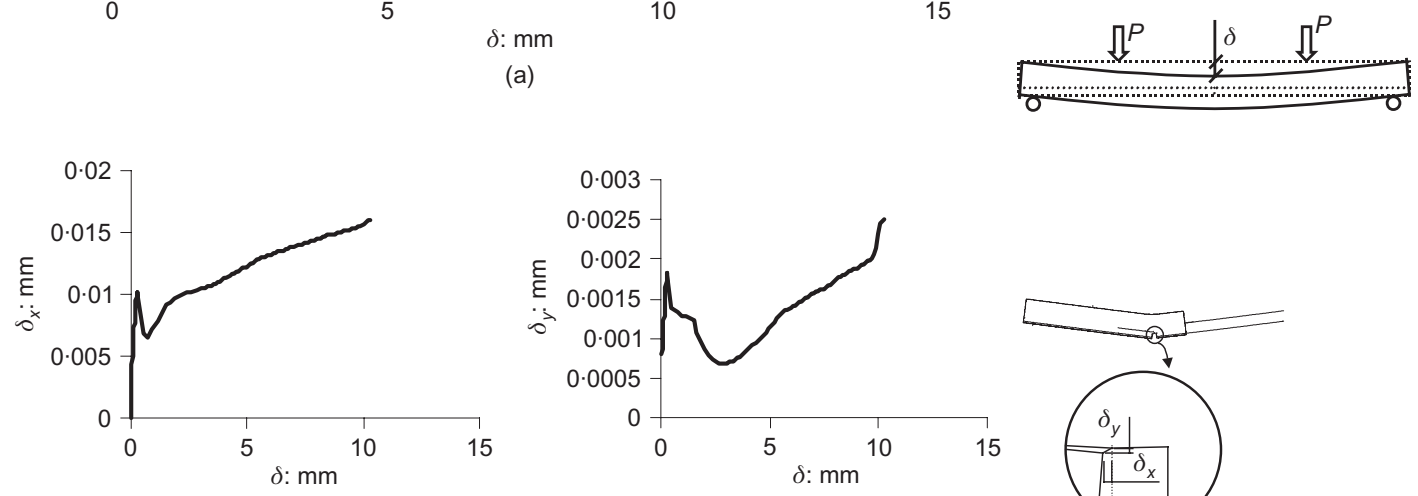

(b)

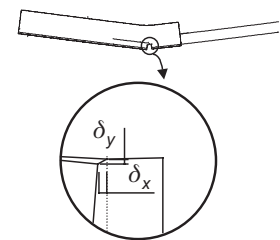

Fig. 22. Results from FEA of brushed surface with half adhesive strength: (a) load plotted against mid-span deflection; (b) deformation in the cast joint plotted against mid-span deflection 
rather imminent in this case; as can be seen in Fig. 22(b), the opening increased just before the analysis could not be continued.

The results from analyses with zero adhesion are shown in Fig. 23. As can be seen, the limiting failure mode was opening of the joint before yielding of the reinforcement could be reached. At maximum load, a bending crack at the lattice girder truss appeared. Then the cast joint opened up, and thus limited the maximum load.

The results from all analyses of full-scale tests are summarised in Fig. 24.

\section{Conclusions}

This study examined the possibility of enabling load carrying in two directions in lattice girder slab systems by complementing with lapped reinforcement across the joints at the construction site. The study was limited to a detailing without any reinforcement crossing the horizontal cast joint between the prefabricated and the in situ cast concrete. Two different surface treatments of the precast elements were studied: with brushing and with single grooves. Detail tests were used to calibrate a model of the cast joint, which was then used in nonlinear FEAs of the full-scale tests. The test specimens with surfaces having single grooves showed a large scatter in the detail tests loaded in shear; in all other tests the scatter was relatively low. Furthermore, the capacity of the cast joint was markedly higher for the brushed surface than for the surface with single grooves: maximum shear stress was around $4 \mathrm{MPa}$ compared with $1 \mathrm{MPa}$, and the adhesive strength was around 1.6 MPa compared with $0.7 \mathrm{MPa}$.

In the full-scale tests, the cast joints were strong enough to carry the applied load. In all full-scale tests the failure mode was rupture after considerable yielding of the reinforcement, and only one crack occurred in the in situ cast concrete above the joint between the precast elements. However, the FEAs of the full-scale tests with prefabricated surface having single grooves

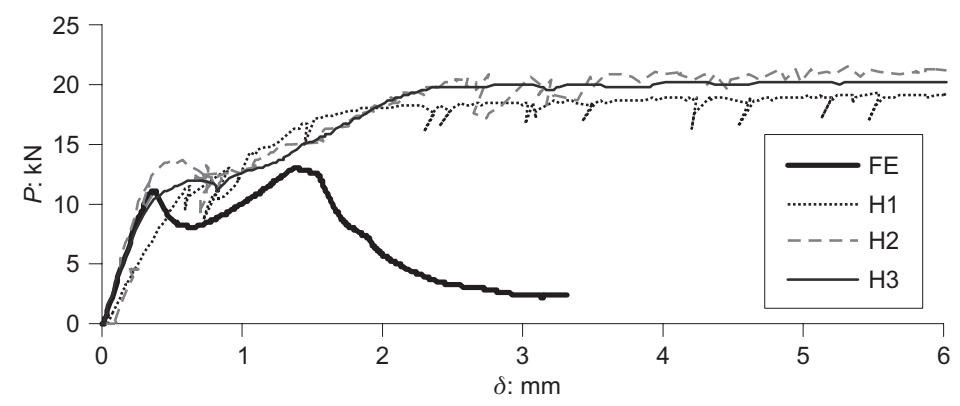

(a)
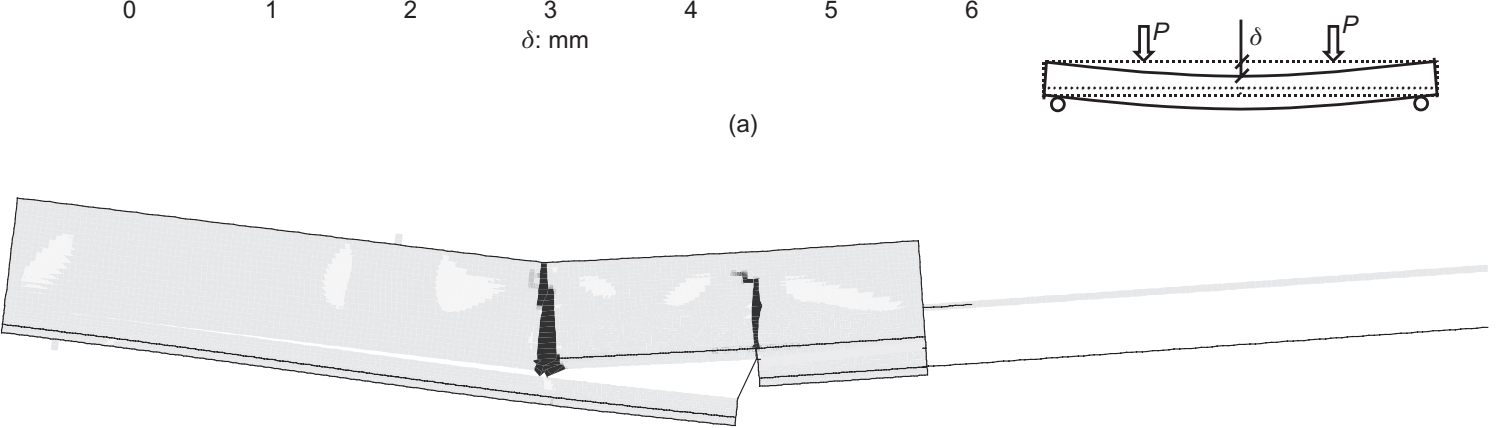

(b)
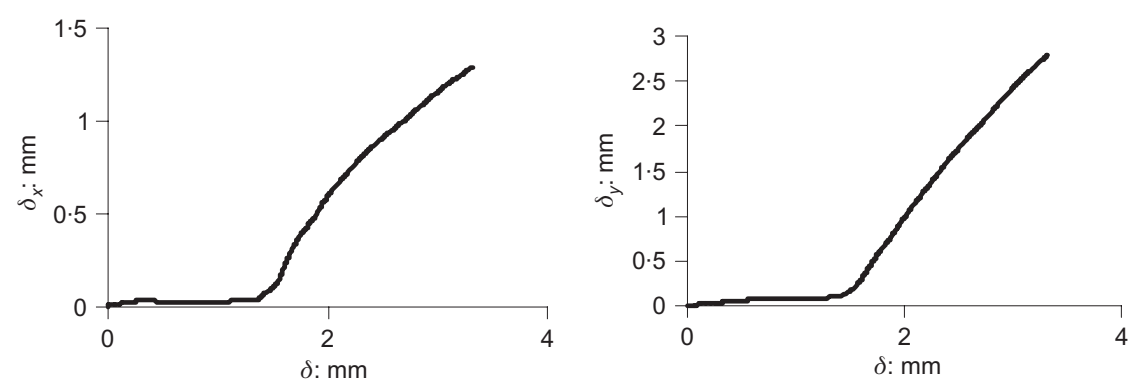

(c)

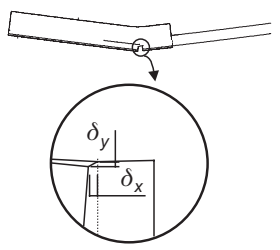

Fig. 23. Results from FEA of brushed surface without adhesion. (a) Load plotted against mid-span deflection; (b) crack pattern and deformed mesh at collapse; (c) deformation in the cast joint plotted against mid-span deflection 


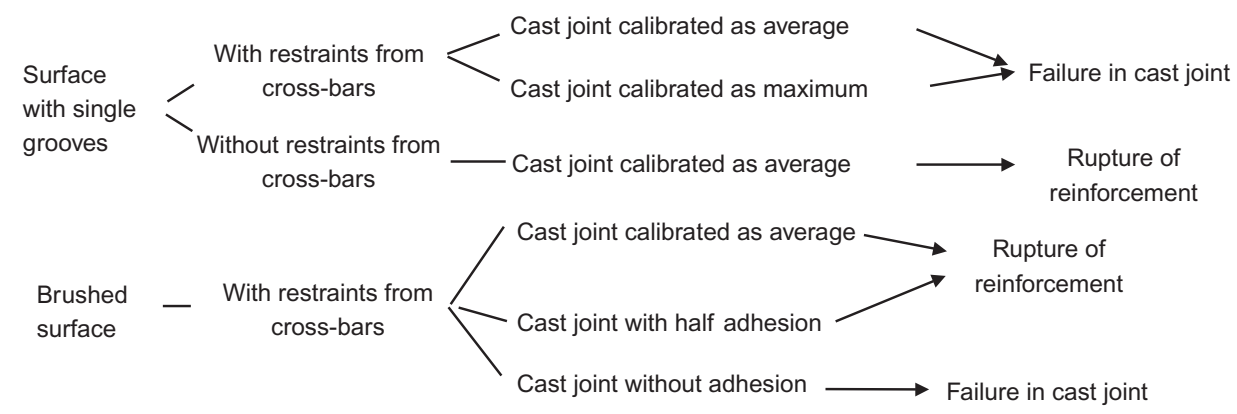

Fig. 24. Results from all analyses of full-scale tests summarised

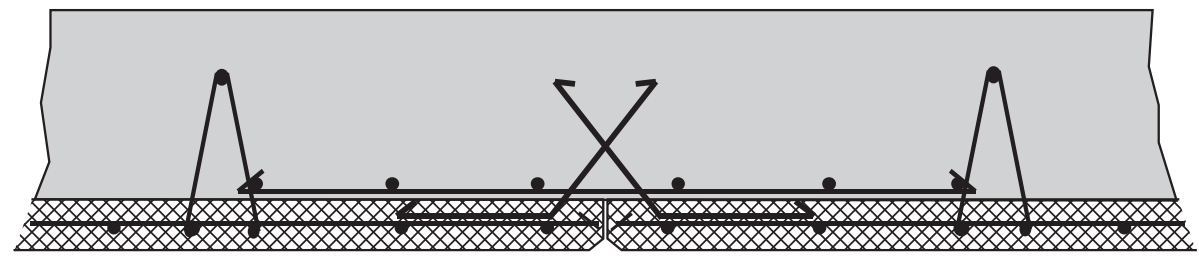

Fig. 25. Alternative detailing with bent reinforcement crossing the cast joint

revealed that the detailing was sensitive to secondary cracking; when restraint from the cross-bars of the reinforcement mesh initiated bending cracks, the failure mode changed to fracture of the cast joint in the analyses. In the analysis where the surface was modelled as brushed, no secondary cracking occurred even when the restraints from the cross-bars were included in the analyses. It is worth noting that in the full-scale tests, the cross-bars were placed directly on the surface of the precast concrete; accordingly they were most likely not so well encased and did not cause any major restraint. Measurements of the strains in the reinforcement support this. Thus, it can be concluded that if the reinforcement mesh were turned upside down, with the reinforcement crossing the joint directly on the precast concrete, this would cause a larger risk for brittle failure than the tested detailing.

From the results, it was concluded that the studied detailing of load-carrying joints between lattice girder slabs without any reinforcement across the cast joint is very sensitive to the roughness of the surface of the prefabricated elements. The detailing relies on the adhesive strength of the cast joint, and there is a risk of premature brittle failures, as was obtained in similar tests by Gudmand-Høyer. ${ }^{4,5}$ These results raise the question of whether reinforcement across the cast joint is needed to guarantee the structural integrity of a structure. It is further concluded that prefabricated elements with surfaces having single grooves cannot be recommended for use in the studied detailing without complementary reinforcement across the cast joint, if the joint is assumed to be load carrying. Considering this, it might however still be possible to use the studied detailing for load-carrying purposes, if a brushed surface is used. Very important demands are that both the production of the surface of the prefabricated ele- ments and the conditions at the work site must be controlled and checked on a regular basis. However, to use the studied detailing in practice for load-carrying purposes, more studies are needed. The demands of the structural behaviour of the grouted joint need to be further clarified, together with methods to measure and control that these demands are met. Furthermore, longterm effects such as sustained loading of the grouted joint, and shrinkage and creep of the concrete were not included in this study, and must be investigated. Other possibilities are to study alternative detailings instead, including reinforcement crossing the joint. By use of reinforcement across the cast joint, the structure would become a lot more robust and could be designed to avoid brittle failures. An important issue is that detailing with reinforcement layouts that lead to rational work on site is addressed. One possibility might be to use bent reinforcement crossing the cast joint, as indicated in Fig. 25.

\section{References}

1. Lundgren K. Analysis of a Lap Splice in a Lattice Girder System. Chalmers University of Technology, Department of Structural Engineering, Concrete Structures, Göteborg, 2003, Report 03:3.

2. Nissen I., Daschner F. and Kupfer H. Versuche zur notwendigen Schubbewehrung zwischen Betonfertigteilen und Ortbeton (Tests of the necessary shear reinforcement between precast concrete elements and in situ concrete. In German). Deutscher Ausschuss für Stahlbeton, 1986, Berlin, report 372.

3. Gohnert M. Horizontal shear transfer across a roughened surface. Cement and Concrete Composites, 2003, 25, No. 3, $379-385$.

4. Gudmand-Høyer T. Forsøg vedr. momentkapaciteten af en speciel samling $i$ BubbleDeck (Tests concerning bending moment capacity of a special detailing in BubbleDeck. In Danish). BYG, DTU, Lyngby, Denmark SR-03-21, 2003.

Magazine of Concrete Research, 2007, 59, No. 10 
5. Gudmand-HøYer T. Forsøg vedr. momentkapaciteten af en samling i BubbleDeck (Tests concerning bending moment capacity of a detailing in BubbleDeck. In Danish). BYG, DTU, Lyngby, Denmark SR-03-20, 2003.

6. Lundgren K., Helgesson J. and Sylvén R. Joints in Lattice Girder Structures. Chalmers University of Technology, Department of Civil and Environmental Engineering, Division of Structural Engineering, Concrete Structures, 2005, Göteborg Report 2005:9.

7. Linsbauer H. N. and Tschegg E. K. Fracture energy determination of concrete with cube shaped specimens. Zement und Beton, 1986, 31, 38-40.

8. Karihaloo B. Fracture Mechanics and Structural Concrete. Longman, Sydney, Australia, 1995.
9. TNO. DIANA Finite Element Analysis, User's Manual Release 8.1. TNO Building and Construction Research, Delft, The Netherlands, 2002.

10. Comité Européen du Béton. CEB-FIP Model Code 1990. Bulletin d'Information 213/214. CEB, Lausanne, Switzerland, 1993.

11. Østergaard L. Early-age Fracture Mechanics and Cracking of Concrete-Experiments and Modelling. $\mathrm{PhD}$ thesis, Department of Civil Engineering, Technical University of Denmark, 2003.

Discussion contributions on this paper should reach the editor by 1 June 2008 